\title{
Effects of hypoxia on force produced by agonists and depolarization and arising spontaneously in the rat uterus
}

\author{
L. Earley and S. Wray \\ The Physiological Laboratory, The University of Liverpool, PO Box 147, Liverpool L69 3BX, UK
}

\begin{abstract}
The effects of cyanide and nitrogen on contractile activity in rat uteri was investigated. Hypoxia significantly reduced contractile activity produced either spontaneously, or by application of carbachol $\left(50 \mu \mathrm{mol} \mathrm{l}^{-1}\right)$ or oxytocin $\left(20 \mathrm{nmol} \mathrm{l}^{-1}\right)$ in preparations from pregnant and nonpregnant rats. Hypoxia had, however, significantly smaller effects on agonist-evoked than on spontaneous contractions. Application of agonists under hypoxic conditions restored some degree of force to preparations in which spontaneous activity had been abolished. This result suggests that the loss of spontaneous contractions was, in part, due to decreased excitability of the uterus, rather than to an impairment of the contractile machinery. Hypoxia significantly decreased the force produced by depolarization of the uterus. The effects of hypoxia on contraction produced by agonists or depolarization were not significantly different, suggesting that a similar mechanism may maintain force under these conditions, and that this mechanism does not occur during spontaneous activity. Lowering the external $\mathrm{Ca}^{2+}$ concentration to $0.1 \mathrm{mmol} \mathrm{l}^{-1}$ resulted in production of significantly less force in the presence or absence of agonist. The ability of hypoxia to decrease agonist-induced force was found not to be due to the intracellular acidification it produces. It was concluded that uterine hypoxia may decrease uterine contractions in vivo and a possible role in dystocia during labour was discussed.
\end{abstract}

\section{Introduction}

Contractions of the uterus occur spontaneously as a consequence of membrane pacemaker activity, which may be maintained by endogenous synthesis of prostaglandins (Coleman and Parkington, 1988; Parkington and Coleman, 1990). Spontaneous contractions are markedly decreased in vitro in rat (Wray et al., 1992) and human (Phoenix and Wray, 1993) uteri when oxidative metabolism is impaired. It has been suggested that if such effects occur in vivo they could underlie some cases of uterine dystocia, a condition of weak, inefficient contractions that causes labour to fail (Wray, 1993). Oxidative metabolism will be impaired during labour, as the powerful uterine contractions lead to occlusion of uterine blood vessels (Greiss, 1965; Brinkman, 1990). During labour, the spontaneous contractions are augmented by hormonal and neuronal stimuli. It is not known what effect blockade of oxidative metabolism has on such agonist-induced uterine contractions. Thus the role of hypoxia in uterine dystocia remains unclear. The purpose of this study, therefore, was to investigate the effect of hypoxia on agonist-induced contractile activity in uteri of pregnant and nonpregnant rats. Data were also obtained from depolarized preparations, and the role of external calcium entry was also investigated, to help establish the mechanism whereby agonists might influence contractions during hypoxia.

It was found that uterine contractions were still diminished during hypoxia in the presence of agonist. However, significantly more force could be maintained in hypoxia in the Received 7 January 1993. presence, rather than in the absence, of agonists. More force could also be maintained in depolarized preparations compared with normally polarized uteri. This finding suggests that greater surface membrane activation may be the mechanism underlying the increased force in hypoxia. In particular, stimulation of external calcium entry appears to be important, as a reduction in external $\left[\mathrm{Ca}^{2+}\right]$ decreased force production.

A preliminary account of some of these results has been presented (Earley and Wray, 1993).

\section{Materials and Methods}

\section{Animals}

Wistar rats were used, either virgin (approximately $200 \mathrm{~g}$ ) or 19-21 days pregnant (parturition occurs on day 22). They were fed Bantam and Kingsman standard rat diet (Kingsman, Hull) and tap water ad libitum.

\section{Tissue preparation and maintenance}

The animals were killed by cervical dislocation under chloroform anaesthesia. In nonpregnant animals, vaginal smears were taken to assess the stage of the ovarian cycle. The uteri were removed and freed of mesentery and any placental sites and fetuses. Uterine strips $(100 \mathrm{mg}$ ) were mounted in a tissue bath containing a solution at $37^{\circ} \mathrm{C}$ of the following composition $\left(\mathrm{mmol} \mathrm{l}^{-1}\right): \mathrm{NaCl} 154, \mathrm{KCl} 5.6, \mathrm{MgSO}_{4}$ 1.2, glucose 11.7, $\mathrm{CaCl}_{2}$ 3. The solution was buffered with $10 \mathrm{mmol}$ Hepes $1^{-1}, \mathrm{pH}$ Downloaded from Bioscientifica com at 04/26/2023 08:57:25AM 
adjusted to 7.4 and gassed with $100 \%$ oxygen. For experimental ease, in the majority of preparations hypoxia was simulated by inhibiting oxidative phosphorylation by adding $2 \mathrm{mmol}$ sodium cyanide $\mathrm{l}^{-1}$ to the bathing solution (external $\mathrm{pH}$ maintained at 7.4). In some experiments oxygen was replaced with nitrogen. Carbachol, an acetylcholine agonist and oxytocin (Sigma, Poole) were used at supramaximal doses $\left(50 \mu \mathrm{mol} \mathrm{l}^{-1}\right.$ and $20 \mathrm{nmol} \mathrm{I}^{-1}$, respectively). In some experiments the $\left[\mathrm{K}^{+}\right]$was raised by equimolar replacement of $40 \mathrm{mmol} \mathrm{Na}{ }^{+} 1^{-1}$. Force was monitored with a Grass transducer (FT03, Quincy, MA). Regular spontaneous contractions were usually established after $30 \mathrm{~min}$ and the bathing solution was then changed to the test solution. As agonists affected the frequency and amplitude of contractions, changes in contractile activity were measured as 'time-averaged force' by integrating the contraction record over unit time (10 min) by cutting and weighing the trace. The records were normalized to control contractions at the start of the experimental period.

\section{Statistical analysis}

Results are expressed as means \pm SEM. Significant differences were tested by the appropriate $t$ test.

\section{Results}

The isolated uteri were maintained for many hours in oxygenated, buffered bathing solution, as described by Heaton et al. (1992). The effects of carbachol and oxytocin often differed between the first and second application. However, the second and subsequent applications gave reproducible responses, and therefore, no data were collected until two applications of agonists had been applied to the tissue. The stage of the ovarian cycle was found to have no influence on the results obtained.

\section{Effects of hypoxia on contractions induced by carbachol}

As expected, carbachol increased uterine contractile activity, in pregnant and nonpregnant uteri. Its action was mainly to increase the frequency of contraction - often to give a more or less maintained contraction (Fig. 1a). There was an increase in the amplitude of contraction (mean increase $12 \pm 2 \%$, in uteri from nonpregnant rats, $n=6$ and $32 \pm 3 \%$ in uteri from pregnant rats, $n=6$ ). When nitrogen was applied to the uterus, spontaneous and carbachol-induced contractile activity was reduced. However, the effects of nitrogen were smaller in the presence than in the absence of agonist (Fig. 1a). Thus, in the absence of agonist, hypoxia quickly abolished all spontaneous activity, whereas hypoxia applied for the same time in the presence of carbachol reduced the amplitude and frequency of the contractions, but did not abolish the contractions. This result was obtained in six nonpregnant preparations, in which the order of presentation of agonist plus nitrogen and nitrogen alone was varied. When cyanide was used to block oxidative phosphorylation $(n=6)$ very similar results were obtained (Fig. Ib). Thus, in most of the subsequent experiments, cyanide rather than nitrogen was used, for experimental ease. It can be seen that the effects of hypoxia on mechanical activity were
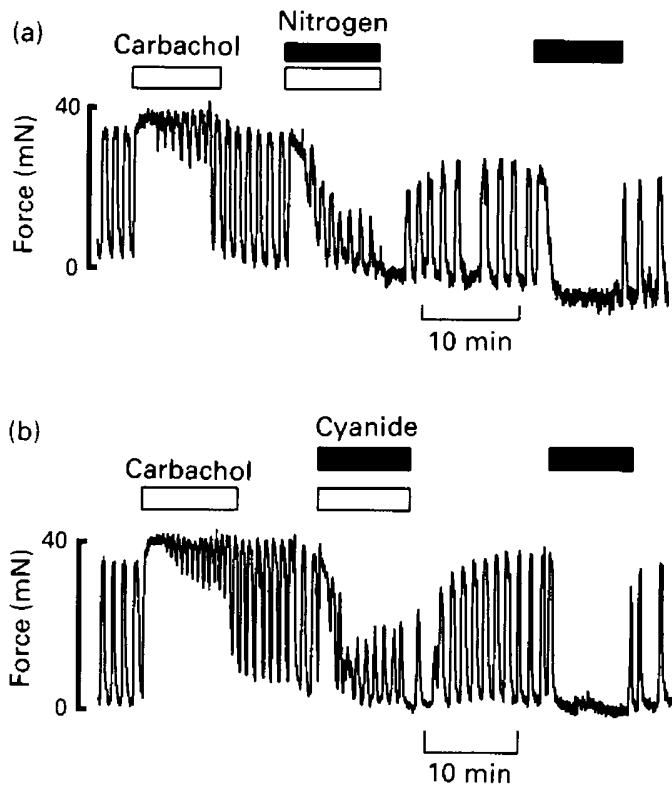

Fig. 1. The effects of hypoxia on uterine contractions. (a) Effects of replacing $\mathrm{O}_{2}$ with $\mathrm{N}_{2}$ ( ) on uterine contractions in the presence and absence of carbachol ( $\square$ ), in uterus of a nonpregnant rat. Contractions occur spontaneously in the absence of agonist. (b) Effects of carbachol ( $\left.\square)(50 \mu \mathrm{mol} \mathrm{I})^{-1}\right)$, carbachol and cyanide ( ) $(2 \mathrm{mmol}$ $\mathrm{I}^{-1}$ ) and cyanide alone on the isolated uterus of a nonpregnant rat. Bars indicate the period over which the test solutions were added.

fully reversed upon return to control solution. The results obtained in uteri of pregnant rats $(n=6)$ were qualitatively similar to those obtained in the uteri of nonpregnant rats (Fig. 2).

The contractile activity was measured by using the integral of contractions, which enables effects on amplitude and on frequency to be taken into account. All data were normalized to control activity at the start of the experimental period. Compared with the activity before application of carbachol, carbachol increased force by 1.77 -fold in nonpregnant preparations and almost threefold in pregnant preparations (Fig. 2). The normalized mean contractile activity in cyanide was approximately three times greater in the presence than in the absence of agonist in nonpregnant preparations $(0.20 \pm 0.02$ compared with $0.64 \pm 0.08$ ) (Fig. 2). The increase was much larger (over sixfold) in pregnant preparations $(0.31 \pm 0.09$ compared with $1.73 \pm 0.28$ ). Force fell in the presence of cyanide to $20 \pm 2 \%$ of control spontaneous contraction but was $36 \pm 4 \%$ of contraction in the presence of carbachol in nonpregnant preparations. The corresponding figures for pregnant preparations are $31 \pm 9 \%$ and $58 \pm 9 \%$, respectively. Thus, irrespective of gestational state, the fall of force in cyanide-treated preparations, relative to carbachol contractile activity, is less than the fall of force relative to control, spontaneous activity.

\section{The effects of hypoxia on oxytocin contractions}

Oxytocin increased the frequency and amplitude of the uterine contraction compared with control spontaneous activity 
(a)

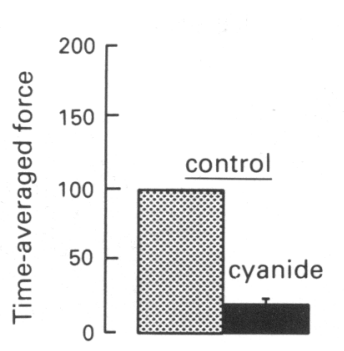

(c)

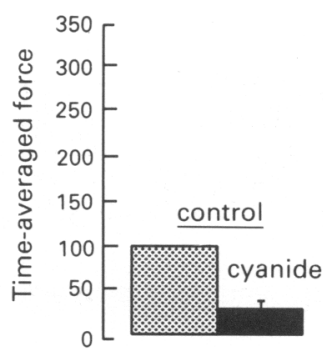

carbachol

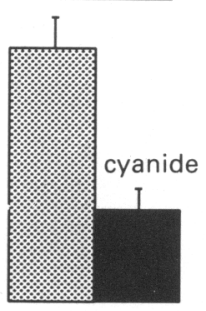

carbachol

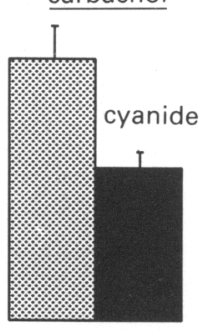

(b)

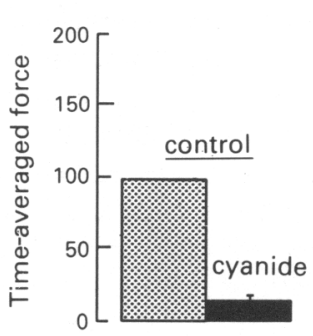

(d)

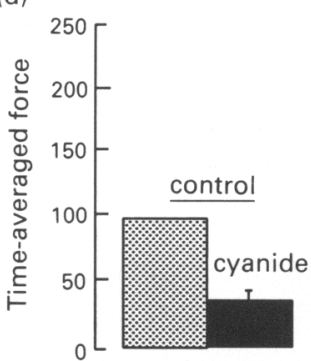

oxytocin

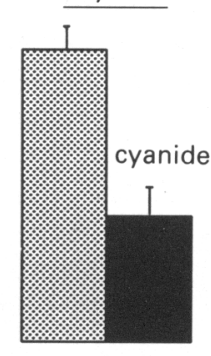

oxytocin

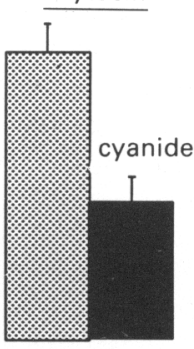

Fig. 2. Mean data from $(a, b)$ nonpregnant and $(c, d)$ pregnant rats showing the effects of cyanide in the presence and absence (control) of agonists on uterine contractile activity. The contraction records were integrated over a unit time, to take into account both frequency and amplitude of the contractions. This is referred to as 'time-averaged force'. Each bar represents mean data from six preparations and the vertical bars show the SEM. Solid bars indicate when cyanide was present. The effects of carbachol and carbachol plus cyanide are compared with control spontaneous contractions (100\% time-averaged force). Agonist for (a) and (c) was carbachol and for (b) and (d) was oxytocin.

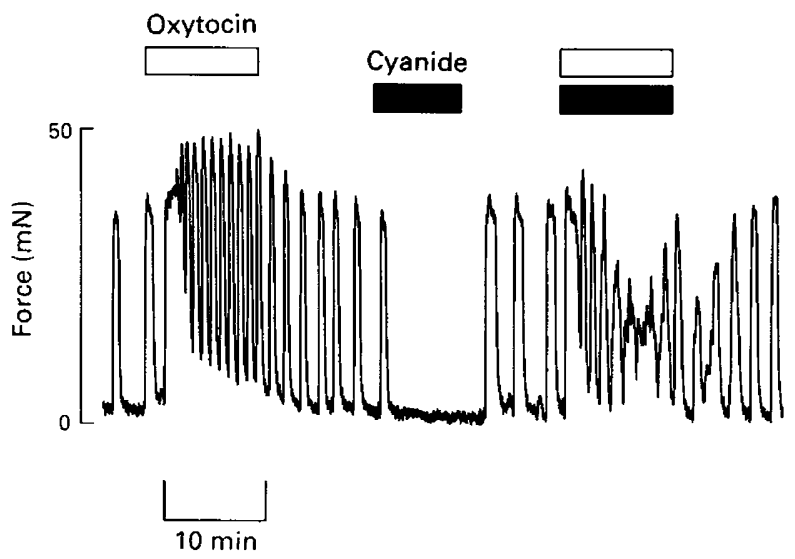

Fig. 3. Effects of oxytocin $(\square)\left(20 \mathrm{~mol} \mathrm{l}^{-1}\right)$, cyanide $(\square)$ and oxytocin plus cyanide, on contractile activity in the uterus of a nonpregnant rat. The bars indicate the period over which the test solutions were added.

in all preparations from pregnant and nonpregnant animals. The mean increase in amplitude was $11 \pm 3 \%$ in uteri from nonpregnant rats $(n=6)$ and $38 \pm 3 \%$ in uteri from pregnant rats $(n=6)$. The effect on frequency was very pronounced (Fig. 3); an example of an increase where the contraction was maintained is shown (Fig. 4). Cyanide reduced contractile activity in the absence and presence of oxytocin. However, the effects of cyanide were much less when oxytocin was present (Fig. 3). The effects of cyanide on mechanical activity were quickly and fully reversed upon return to control solution. The mean data show, as was found for carbachol, that with cyanide much more contractile activity remained when oxytocin was present (Fig. 2). The mean contractile activity with cyanide in uteri of nonpregnant rats was $14 \pm 2 \%$ in the absence and $89 \pm 20 \%$ in the presence of agonist. In uteri of pregnant rats, the corresponding figures were $35 \pm 9 \%$ and $106 \pm 22 \%$, respectively. When the changes in cyanide were expressed relative to control, spontaneous activity and oxytocin contractile activity, cyanide reduced spontaneous force to $14 \pm 2 \%$ and oxytocin-induced force to $43 \pm 10 \%$ in uteri of nonpregnant rats and $35 \pm 9$ and $47 \pm 10 \%$, respectively, in uteri of pregnant rats. Thus, in the presence of either carbachol or oxytocin, the uterus of pregnant rats could produce about $50 \%$ of its normal contractile activity during hypoxia.

\section{Comparison of the effects of cyanide on agonist and depolarized contractile activity}

The above results show that there was significantly greater force produced by the uterus in cyanide when it was activated by agonists. Many agonists increase force by causing depolarization of the myometrial surface membrane (see Wray, 1993 for a review). The depolarization caused $\mathrm{Ca}^{2+}$ entry via voltage-gated channels. The effects of agonists were compared with those of high- $\mathrm{K}^{+}$solution to determine whether the effect 


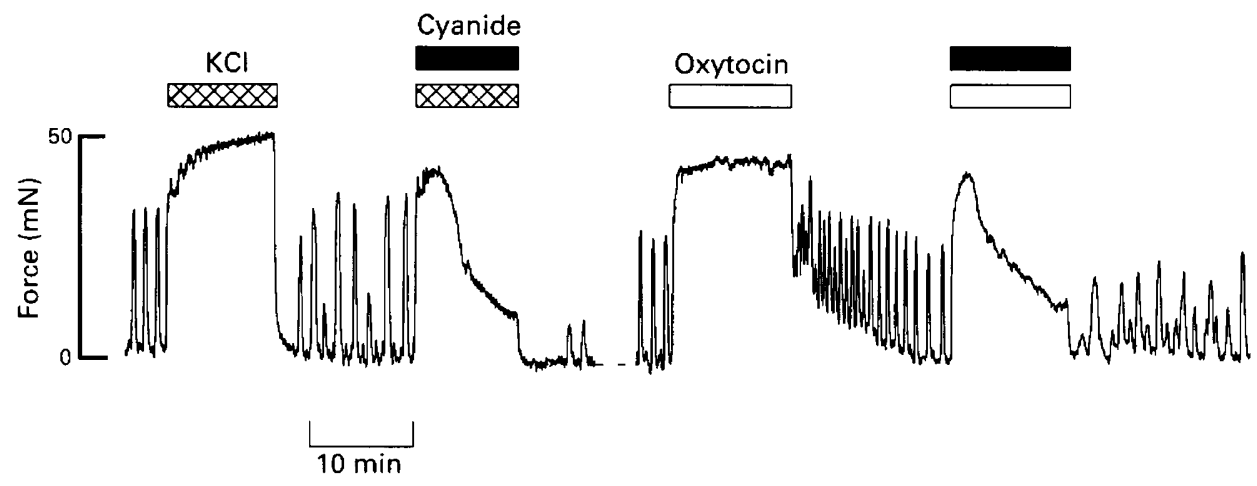

Fig. 4. The effects of depolarization ( $40 \mathrm{mmol} \mathrm{K} \mathrm{K}^{+1}$ solution) ( $\square$ ) or oxytocin ( $\square$ ), with cyanide ( $)$ and without cyanide in the uterus of a nonpregnant rat. The dotted line indicates an interruption in the recording. The bars indicate the period over which the test solutions were added.

of the agonists in increasing force production in cyanide could be due to surface membrane depolarization.

In eight preparations, the effects of cyanide in the presence of oxytocin, carbachol or high- $\mathrm{K}^{+}$solution were examined. A typical result is shown (Fig. 4). High- $\mathrm{K}^{+}$solution produced a maintained contraction of the uterus. If high- $\mathrm{K}^{+}$and cyanide were applied simultaneously, force was initially maintained but then decreased towards baseline values (Fig. 4). Upon return to control solution, spontaneous contractions gradually reappeared. When oxytocin and cyanide were applied to the same preparation, a very similar pattern of contractile activity occurred, i.e. force was initially maintained and then fell to baseline values. The mean contractile activity in oxytocin and cyanide relative to oxytocin alone was $37 \pm 5 \%$. This was not significantly different from the figure of $39 \pm 8 \%$ obtained for high- $\mathrm{K}^{+}$and cyanide, relative to high- $\mathrm{K}^{+}$alone. Again, when carbachol was used, there was no significant difference; the values were $36 \pm 5 \%$ and $41 \pm 8 \%$ for carbachol plus cyanide and high- $\mathrm{K}^{+}$plus cyanide, respectively.

\section{Effect of agonist following abolition of spontaneous contractions by cyanide}

The above results are consistent with the contention that the depolarizing actions of the agonists lead to the increased contractile activity in cyanide compared with spontaneous activity in the absence of agonist. It has been shown that decreased surface membrane electrical activity is, at least in part, responsible for the initial abolition of spontaneous uterine contractions (Heaton et al., 1993). Thus, it would be expected that in a preparation in which spontaneous contractions had been abolished by cyanide, that application of agonist, in the continued presence of cyanide, should elicit some force from the uterus. This was therefore investigated.

In four nonpregnant preparations, carbachol was applied after a period in cyanide sufficient to ensure that all spontaneous activity had been abolished (approximately 3-4 min). Application of carbachol, in the continued presence of cyanide, immediately elicited contraction from the uterus (Fig. 5). The mean amplitude of such contractions was $32 \pm 5 \%$ of the

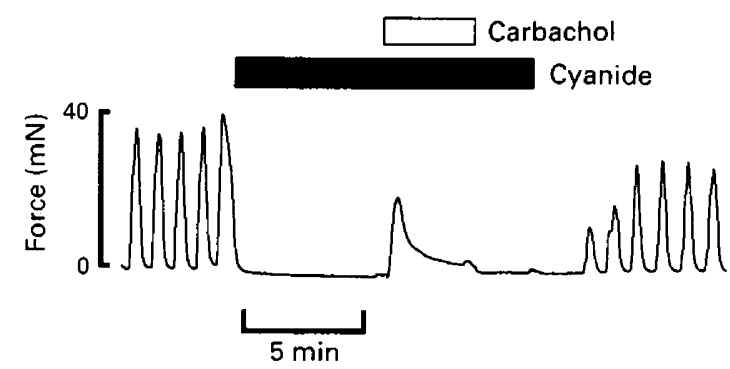

Fig. 5. Effect of carbachol ( $\square$ ) on contraction of the uterus of a nonpregnant rat, following abolition of spontaneous contractions by cyanide ( ). Note that cyanide was still present when carbachol was added. The bars indicate the period over which the test solutions were added.

amplitude of control contractions. The contraction gradually returned towards baseline tension values.

\section{Does acidification depress agonist-induced contractions?}

The data obtained so far show that cyanide depresses agonist-induced contractile activity in the uterus. Cyanide causes an intracellular acidification and a reduction in ATP concentration (Wray, 1990), both of which may produce a fall in force (Wray et al., 1992). The weak acid butyrate was used to acidify the myometrial cells to determine the role of decreased $\mathrm{pH}$ on the depression of agonist-induced contractions. Butyrate was used at a concentration $\left(40 \mathrm{mmol} \mathrm{l}^{-1}\right)$ that produces an equivalent acidosis to that of cyanide $(0.3 \mathrm{pH}$ unit, Wray, 1990 and M. J. Taggart and S. Wray, unpublished observations). Thus $\mathrm{pH}$ changes without changes in ATP concentration could be investigated.

Butyrate $\left(40 \mathrm{mmol} \mathrm{l}^{-1}\right)$ significantly decreased spontaneous force in all eight preparations from nonpregnant animals tested. A typical example is shown (Fig. 6). It can be seen that there is recovery of spontaneous contractions in the continued presence of butyrate, presumably because $\mathrm{pH}_{\mathrm{i}}$ was recovering to resting values due to $\mathrm{pH}$ regulation (Eisland et al., 1991). Butyrate transiently abolished spontaneous force but had no significant 


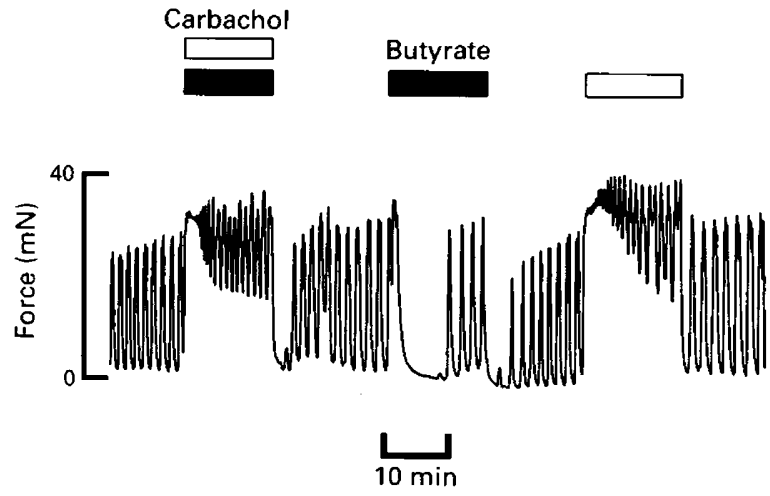

Fig. 6. The effects of carbachol ( $\square$ ), butyrate ( $\square)\left(40 \mathrm{mmol} \mathrm{l}^{-1}\right)$, and butyrate plus carbachol on uterine contractile activity. The bars indicate the period over which the test solutions were added.

effect on carbachol- $(n=4)$ or oxytocin-induced $(n=4)$ contractions.

\section{Effect of reduced external $\left[\mathrm{Ca}^{2+}\right]$ on agonist-induced contraction}

The role of calcium entry in the effects of agonists on contraction was examined by lowering the $\left[\mathrm{Ca}^{2+}\right]$ in the external solution from 3 to 1 and $0.1 \mathrm{mmol} \mathrm{l}^{-1}$. (The uterus does not contract if all external calcium is removed.) Lowering external $\mathrm{Ca}^{2+}$ to $1 \mathrm{mmol} \mathrm{l}^{-1}$ had no significant effect on either spontaneous or agonist-induced contractions $(n=4)$. At $0.1 \mathrm{mmol}$ external $\mathrm{Ca}^{2+} 1^{-1}$, there was a significant $(P<0.05)$ decrease in carbachol-induced contractile activity, compared with the effects obtained with $3 \mathrm{mmol}$ calcium $\mathrm{l}^{-1}$ ( $n=4$ preparations from nonpregnant animals). Thus, compared with control spontaneous contractions, carbachol increased contractile activity by 2.49-fold in $3 \mathrm{mmol} \mathrm{Ca}^{2+} \mathrm{l}^{-1}$ and 1.98 -fold in $0.1 \mathrm{mmol} \mathrm{Ca}^{2+} \mathrm{l}^{-1}$. Similarly, the amount of force obtained in carbachol and cyanide was significantly less at $0.1 \mathrm{mmol} \mathrm{Ca} \mathrm{Ca}^{2+} 1^{-1}$ compared with $3 \mathrm{mmol} \mathrm{l}^{-1}(0.53 \pm 0.08$ and $0.75 \pm 0.09$, respectively). However, the amounts of force produced in cyanide, relative to carbachol alone, were similar at the two calcium concentrations; thus, the ratio of carbachol and cyanide to carbachol was 0.26 in $0.1 \mathrm{mmol} \mathrm{Ca}{ }^{2+} \mathrm{l}^{-1}$ and 0.30 in $3 \mathrm{mmol} \mathrm{Ca}{ }^{2+} \mathrm{l}^{-1}$.

\section{Discussion}

The data obtained show that cyanide and nitrogen significantly reduce contractile force in the uterus, whether produced spontaneously, by depolarization or by agonists. Thus, hypoxia in vivo may depress contractions and contribute to uterine dystocia in labour (discussed below). The data also show that the fall of force in the presence of cyanide was significantly reduced when agonist was present. For example, in the uterus of pregnant rats, without agonist present, cyanide reduced force to approximately $30 \%$ of control values. When agonist was present, cyanide reduced force to about $50 \%$ of control values (i.e. agonist alone).

The uteri of pregnant animals produced more force than the uteri of nonpregnant animals under all conditions. Even when force is normalized to control values, more force is produced in cyanide by the uterus of pregnant than of nonpregnant rats. When agonists and cyanide were present this difference was also seen. Thus, in carbachol and cyanide the uterus of nonpregnant rats produced $36 \pm 4 \%$ and the uterus of pregnant rats $58 \pm 9 \%$ compared with control contractile activity.

Previous studies, mainly on spontaneous contractions of isolated rat uterus, have shown that cyanide causes: (i) a significant decrease in $\mathrm{pH}_{\mathrm{i}^{\prime}}$ (ii) an increase of $\mathrm{K}^{+}$efflux and, hence, a decreased membrane excitability and (iii) the concentrations of ATP and phosphocreatine to fall, while inorganic phosphate $\left(\mathrm{P}_{\mathrm{i}}\right)$ rises (Wray, 1990; Heaton et al., 1993). Each of these three changes have been shown to decrease spontaneous contractile activity (Wray et al., 1992; Crichton et al., 1993; Heaton et al., 1993) and will be discussed below.

The experiments in which the weak acid butyrate was applied to reduce $\mathrm{pH}_{\mathrm{i}}$ in the presence of oxytocin or carbachol (Fig. 6) show that a fall in $\mathrm{pH}_{\mathrm{i}}$ does not reduce agonist-induced contraction. Thus, agonist stimulation of the contractile system can over-ride the depression produced by $\mathrm{H}^{+}$, possibly by causing a greater rise in $\left[\mathrm{Ca}^{2+}\right]_{\mathrm{i}}$. A fall in $\mathrm{pH}_{\mathrm{i}}$ therefore does not appear to be the cause of the fall of agonist-induced force in cyanide.

A depression of surface membrane excitability may be responsible for at least the earlier loss of spontaneous activity. Contraction can be elicited in the continued presence of cyanide following abolition of spontaneous contraction by adding agonist. High- $\mathrm{K}^{+}$depolarization can also do this (Heaton $e t$ al., 1993). This result suggests that the contractile machinery can still produce contraction, but that it is not being excited. However, the contraction elicited by agonist application, under these conditions, is of reduced amplitude and is transient. The most straightforward explanation is that ATP and phosphocreatine concentrations are gradually falling when cyanide is present and contraction becomes compromised. An increase in $\left[\mathrm{P}_{\mathrm{i}}\right]$ may also reduce force, as experiments with skinned myometrial preparations have shown (Crichton et al., 1993). Thus, a combination of reduced surface membrane excitability and changes in myometrial metabolites probably underlies the fall of force.

It is not known by what mechanism the agonists enable the uterus to produce more force during cyanide application. It may be that greater concentrations of $\left[\mathrm{Ca}^{2+}\right]_{i}$ are obtained in the presence of agonist than occur with spontaneous contractions in their absence. Supramaximal doses of agonists were used to obtain uniform responses from the different preparations. The differences between spontaneous contractions and those evoked by agonists may not be so great at lower agonist concentrations. However, it was found that the effects of agonists could be replicated by simply depolarizing the uterus. Thus, while this result does not rule out the effects of receptoroperated channels or agonist-induced sensitization of contractile machinery, it is at least consistent with a role for surface membrane depolarization by agonists being sufficient to account for the effects observed. Measurement of $\left[\mathrm{Ca}^{2+}\right]_{\mathrm{i}}$ under these conditions would clearly add to our understanding. Reduction of external $\mathrm{Ca}^{2+}$ reduced both spontaneous and agonistinduced contractile activity, confirming the importance of $\mathrm{Ca}^{2+}$ influx to development of uterine force. Lowering of external $\mathrm{Ca}^{2+}$ did not, however, change the effect of hypoxia on the uterus. 
It is known that the blood flow to the uterus diminishes during each labour contraction as the blood vessels become occluded (Greiss, 1965; Brinkman, 1990). Thus, the uterus in labour will experience conditions of ischaemia and hypoxia. These effects are transmitted to the fetus, as judged by the fetal tachycardia often associated with the peak of each contraction and the fact that long labours with prolonged and forceful contractions are associated with fetal distress (Brace, 1986). The work reported here suggests that the uterus is itself affected by hypoxia. Thus, as hypoxia is produced in the uterus, so the contraction will start to fail - despite neuronal and hormonal stimulation. It may be that if, in some women, the uterus is particularly sensitive to the changes that occur in hypoxia, then only weak contractions will be produced. This could therefore present as dystocia in labour.

The authors are grateful to the MRC and the Wellcome Trust for supporting this work.

\section{References}

Brace RA (1986) Fetal blood volume responses to acute fetal hypoxia American Joumal of Obstetrics and Gynecology 155 889-893

Brinkman CR (1990) Circulation in the pregnant uterus. In Uterine Function, molecular and cellular aspects, pp 519-537 Eds ME Carsteb and JD Miller. Plenum Press: New York
Coleman HA and Parkington HC (1988) Induction of prolonged excitability in myometrium of pregnant guinea-pigs by prostaglandin $\mathrm{F}_{2 a}$ Joumal of Physiology 399 33-47

Crichton CA, Taggart MJ, Wray S and Smith GL (1993) Effects of pH and inorganic phosphate on force production in $\alpha$-toxin permeabilized isolated rat uterine smooth muscle Journal of Physiology 465, 629-645

Earley L and Wray S (1993) The effects of cyanide on agonist-induced contractile activity in isolated rat uterus Journal of Physiology 459490

Eiesland J, Baro I, Raimbach S, Eisner DA and Wray S (1991) Intracellular $\mathrm{pH}$ and buffering power measured in isolated single cells from pregnant rat uterus Experimental Physiology 76 815-818

Greiss FC (1965) Effect of labour on uterine blood flow American Journal of Obstetrics and Gynecology 93 917-923

Heaton RC, Taggart MJ and Wray S (1992) The effects of intracellular and extracellular alkalinization on contractions of the isolated uterus Pflugers Archiv 422 24-30

Heaton RC, Wray S and Eisner DA (1993) Effects of metabolic inhibition and changes of intracellular $\mathrm{pH}$ on potassium permeability and contraction of rat uterus Journal of Physiology 465 43-56

Parkington HC and Coleman HA (1990) The role of membrane potential in the control of uterine motility. In Uterine Function: Molecular and Cellular Aspects pp 195-248 Eds ME Carsten and JD Miller. Plenum Press, New York

Phoenix J and Wray S (1993) Changes in frequency and force production of the human myometrium with alteration of $\mathrm{pH}$ and metabolism Journal of Reproduction and Fertility 97 507-512

Wray S (1990) The effects of metabolic inhibition on uterine metabolism and intracellular $\mathrm{pH}$ in the rat Joumal of Physiology $423411-423$

Wray S (1993) Uterine contraction and physiological mechanisms of modulation American Journal of Physiology $264 \mathrm{CI}-\mathrm{C} 18$

Wray S, Duggins K, lles R, Nyman L and Osman VA (1992) The effects of metabolic inhibition and intracellular $\mathrm{pH}$ on rat uterine force production Experimental Physiology 77 307-319 